NASZA DERMATOLOGIA Onlin OUR DERMATOLOGY Online

Source of Support: Nil

Competing Interests: None

\section{EARLY DIAGNOSIS OF THE COLON CARCINOMA DURING THE TREATMENT WITH ACITRETIN}

\author{
Ilteris Oguz Topal ${ }^{1}$, Yunus Topal ${ }^{2}$, Nilgun Bahcetepe ${ }^{1}$, Sule Gungor ${ }^{1}$ \\ ${ }^{I}$ Department of Dermatology, Okmeydani Research and Training Hospital, Istanbul, \\ Turkey \\ ${ }^{2}$ Department of General Surgery, Taksim Research and Training Hospital, Istanbul, \\ Turkey
}

Corresponding author: Dr Ilteris Oguz Topal

drilteris@yahoo.com
Sir,

Acitretin is a systemic retinoid drug used in the treatment of severe psoriasis and various other skin disorders, such as lichen planus, ichthyosis, lupus erythematosus. The mechanism of action of acitretin is still incompletely understood although, like retinoic acid, it is thought to interfere with the terminal differentiation of keratinocytes. The most frequent adverse reactions associated with this drug are the mucocutaneous effects on the lips, eyes, mouth, and other epidermal surfaces [1]. Herein, we present a case of a 54-year old man who developed rectal bleeding and detection of early stage colon carcinoma during the treatment with systemic acitretin for psoriasis vulgaris. A 54-year old man with 15-year history of psoriasis vulgaris, resistant to several topical agents, was presented to our out-patient clinic. He had generalised erythematous plaques. His only other medical problem was diabetes mellitus. Routine laboratory tests were normal. Therapy with oral acitretin $(25 \mathrm{mg} /$ day $)$ was initiated. A month after starting the acitretin treatment, he developed symptoms of rectal bleeding which was intensified by defecation. He also complained of cheilitis, xerosis, and eye dryness. The patient was referred to department of general surgery. Abdominal examination was unremarkable. Pelvic ultrasonography did not revealed any abnormalities. Stool examination for occult blood was negative, and tumor markers (CEA, CA19.9) were normal. The colonoscopy was performed and this revealed a flat polyp measuring $2,5 \times 1,7 \times 1,5 \mathrm{~cm}$ located in the sigmoid colon. Snear polypectomy was performed. A histological evaluation revealed a well differentiated adenocarcinoma penetrating the submucosa. Histologically, the tumor was composed of neoplastic cells that had invaded the lamina propria without venous or perineural invasion. Abdominal computed tomography (CT) and CT scanning with positron-emission tomography (PET-CT) showed no evidence of primary lesions or distant metastasis. Based on clinical and histopathological features, a diagnosis of early stage colon carcinoma was made. We suspected that the acitretin was causing the complaints and recommended discontinuation of the drug. Once this occurred, the problems subsided gradually over the next two weeks.

Acitretin is a retinoid drug used for systemic treatment of severe cases of psoriasis and keratinization disorders. The most common side-effects of acitretin are dry lips and cheilitis, occuring in up to $75-100 \%$ of patients. Other mucocutaneous effects include conjunctivitis, dry nose, epistaxis and sticky skin $[1,2]$. Rectal bleeding are not commonly documented side effects in dermatological practice. Previously, Erpolat et al. reported a case who developed anal fissures, rectal bleeding soon after receiving systemic retinoid therapy [3]. But detection of occult malignancy after the use of acitretin has never been documented. Interestingly, our patient had a malignancy but he was not aware of this condition. Because the tumor was very small and did not caused any symptoms, we think that the rectal bleeding was caused by the acitretin as it related to the dryness of the rectal mucosa. Rectal bleeding can be occured as a result of trauma, such as forceful defecation in xerotic, fissured rectal mucosa. As a result, the use of the acitretin in our patient caused the rectal bleeding and provided early diagnosis of the colon carcinoma. It can be said that clinicians should be aware of the possible mucocutaneous side effects of acitretin. These side effects sometimes may provide detection of occult malignancy.

\section{REFERENCES}

1. Li W, Liu Y, Luo Q, Li XM, Zhang XB. Off-label uses of retinoids in dermatology. Our Dermatol Online. 2012;3(Suppl.1):259-78.

2. Dunn LK, Gaar LR, Yentzer BA, O’Neill JL, Feldman SR. Acitretin in dermatology: a review. J Drugs Dermatol. 2011;10:772-82.

3. Erpolat S, Gorpelioglu C, Sarifakioglu E. Isotretinoin associated anal fissure and rectal bleeding: a rare complication. Int J Dermatol. $2012 ; 51: 358-9$

Copyright by Ilteris Oguz Topal, et al. This is an open access article distributed under the terms of the Creative Commons Attribution License, which permits unrestricted use, distribution, and reproduction in any medium, provided the original author and source are credited. 